\title{
Attitudes towards, and methods of, maintaining or losing body weight among adults
}

\author{
Peter Buzzacott ${ }^{1 *}$, Sarah French $^{2}$, Lisa Wood $^{2}$, Michael Rosenberg $^{1}$ \\ ${ }^{1}$ School of Sports Science, Exercise and Health, The University of Western Australia, Perth, Australia; \\ ${ }^{*}$ Corresponding Author: peter.buzzacott@uwa.edu.au \\ ${ }^{2}$ Centre for the Built Environment and Health, The University of Western Australia, Perth, Australia
}

Received 9 January 2013; revised 8 February 2013; accepted 15 February 2013

\section{ABSTRACT}

To investigate motivators and strategies of adult weight loss or management, 1805 adults aged 18 - 65 were asked by computer assisted telephone interviews about their weight management behavior during the previous four weeks. High levels of importance to reduce risks associated with chronic diseases such as cancer, heart disease and diabetes were observed, although were indistinguishable between people attempting or not attempting to lose or maintain weight. Results showed that BMI was the strongest predictor of attempting to manage weight irrespective of age and, compared with males, females were more likely to attempt weight management at a lower BMI. Among the weight management group, the most popular weight management strategy was to choose healthier food options (77\% and $70 \%$ for females and males respectively). With the weight management group also more likely to be monitoring the amount of food they consume, limiting portions sizes and tracking their physical activity participation compared with people not managing their weight. The current study showed that the likelihood of weight management within four weeks prior to the survey peaked for both sexes when BMI reached obese levels, $(B M I=30-39.9)$, suggesting that among people categorised as obese most were attempting to manage their weight. The results also suggest that at least some adults were not attempting to maintain their weight in the four weeks prior to the survey, irrespective of their BMI status. The implications of these findings suggest more effective approaches to weight loss and maintenance could focus on strategies that directly address the benefits and motivations of weight loss and weight maintenance, rather than focusing on conveying the risks of being overweight and the importance of avoiding chronic disease.

Keywords: Body Mass Index; Body Weight Changes; Obesity; Overweight

\section{INTRODUCTION}

Obesity prevalence among adult Australians continues to increase and as a result the burden of disease attributeable solely to high body mass ( $7.5 \%$ of total burden) is now very close to, and likely to overtake, tobacco (7.8\%) as the leading modifiable cause of disease burden [1]. The World Health Organization report at least one billion adults now overweight; at least 300 million of them clinically obese [2]. Obesity is now a major contributor to the global burden of chronic disease and disability and its prevention is an international priority $[2,3]$.

The act of maintaining or losing weight is complex, involving many decisions, ultimately around when and how much energy to consume and expend [3]. Individual attitudes to lose or maintain weight and subsequent behavioural actions have been shown, above all other factors, to culminate in a realisation to act. This realisation could come as a jarring reminder or trigger, or as a slow dawning acceptance that losing weight is beneficial $[4,5]$. Whether the realisation arises from a comment by a friend, family member or physician, an underlying health problem, fear of ill health, or more practical issues, (such as clothing becoming too tight), it is important to identify correlates of people's motivation to lose or maintain their weight in order to develop effective approaches to address overweight and obesity [6-8].

Previous studies have found socio-demographic characteristics such as age, sex, socio-economic status, income and education level to be associated with intention to lose or maintain weight [8]. Age has been reported as one of the demographic predictors of weight management, however the relationship between age and weight loss or maintenance is unclear because the prevalence of trying to lose weight increases with Body Mass Index 
(BMI) [9], and BMI increases with age [10]. Also increasing with age is interest in health and nutrition, with older adults more likely to care about their health and engage in weight management activities [10]. Furthermore, Blosktra reported that age was not as significant a factor among men as among women in trying to lose weight, suggesting a confounding effect of age on attitude to maintain or lose weight due to real or perceived BMI [10].

Gender as a moderating effect on weight perception and weight management practices has been documented with men found more likely than women to underestimate their weight [11], less likely to be trying to lose weight [12], and more likely to be motivated to lose weight because of physical health limitations [12]. Blokstra et al. reported that the majority of men described their weight as "just right" unless they were obese, unlike women who tended to overestimate adiposity [10]. Men have also been found more likely than women to disagree that their excess weight is a health risk [13-15]. The importance placed on women's physical appearance and body shape is also a contributing factor to the difference between genders with women reporting much stronger histories of attempted weight loss than men [10]. Men, therefore, have been found trying to lose weight to a lesser extent than women [3]. Men in particular choose not to lose weight due to a lack of motivation or perceived barriers towards weight reduction such as commitments at work, the financial expense of healthy eating, finding time to exercise or too easily slipping back into familiar habits [16]. Men choose to lose weight to feel better [3], or to increase their effectiveness in the workplace, while being lean and general health does not appear to be motivational for males [6].

A number of psycho and socio-graphic variables have also been associated with weight maintenance including a person's perception of health risk, their perceived body size and doctor's advice to lose weight $[12,13]$. Attitudinal factors associated with long-term weight loss maintenance include initial readiness and motivation to change, autonomous motivation, regulatory focus and less life satisfaction prior to weight loss [17-20]. While health may be the primary reason provided for managing weight, self-esteem and appearance have also been found to be motivators, especially for women. A medical event or advice from a general practitioner have been reported as motivators for change [4]. While health is associated with maintaining or losing weight there is little breakdown of whether risk of chronic disease such as cancer, heart disease or diabetes stimulate behaviour change.

Once individuals decide to maintain or lose weight then modifying their diet and increasing physical activity are the most prevalent lifestyle modifications [9] and caloric restriction is reported as the most common method of weight loss [10]. The manner in which people choose to reduce caloric intake varies from making better food choices to eating less, starvation, meal replacement, liquefied formula, pharmalogical agents or surgical procedures $[9,21]$. Dutta et al. profiled healthy eating consumers and found that women were more likely than men to engage in healthy eating, with healthy eaters being older and more educated [22].

The aim of this study was to identify differences in characteristics, attitudes towards health and behavioural actions between adults who have recently attempted to maintain or lose weight and those adults who have not.

\section{METHODS}

\subsection{Sample}

Data were collected from a survey developed to evaluate the impact of the Draw the Line mass media campaign aimed at preventing unhealthy weight gain among West Australian adults. Cross-sectional data were collected on three occasions during 2009 and 2010 using computer assisted telephone interviewing. Respondents were selected randomly from the electronic Western Australian White Pages. Strategies implemented to ensure quality data collection and response rate included up to 10 call backs to obtain a contact, selecting household members with the most recent birthday, comprehensive interviewer training and interview monitoring. The research protocol was approved by the University of Western Australia Human Research Ethics Committee. In total 1805 West Australians aged 16 - 65 were surveyed. There were no statistically significant demographic differences between the three collection groups, thus it was considered appropriate to pool the survey data.

\subsection{Measures}

Socio-demographic characteristics: Demographic data included sex, age group, postcode, income, education level, height and weight. Place of residence, metropolitan Perth or regional Western Australia (WA), was derived from the postcode. The measure of socio-economic status (SES) was derived from the Australian Bureau of Statistics Socio-Economic Index for Areas (SEIFA), an index of relative socio-economic advantage and disadvantage [23]. Respondents were categorised into SES tertiles based on WA population SEIFA data.

Body Mass Index: Self-reported height and weight were collected to calculate BMI for each respondent by dividing weight in kilograms by the square of height in metres.

Weight management behaviour: Respondents were asked if, during the last four weeks, they had attempted to lose weight, not gain weight or not been concerned 
about their weight. Weight management behaviour was then collapsed into those who were managing their weight (attempted to lose or not gain weight) (MW) and those not concerned about their weight, who were not actively managing their weight (Not-MW).

Health values: The importance of health and maintaining a healthy weight was assessed by eleven items regarding attitudes towards risk of chronic disease and weight status as well as internal and external influences on health. A three point Likert scale was used for each statement to detect degree of importance. Statements included "How important is it to you to do things to lower your risk of heart disease, follow recommended health guidelines, maintain a healthy weight or set a good example for others?".

Behaviour: Nine items with six point Likert response scales were used to assess the frequency that respondents engaged in weight monitoring behaviours. Respondents who reported "often", "almost always" or "always" carrying out the behaviour were considered to be "frequent" adopters of the behaviour. The behaviour items were taken from the Nothwehr weight management scale [24], and included elements of diet and activity monitoring, portion control and social interaction.

\subsection{Analysis}

Data were imported into Statistical Analysis System (SAS) version 9.2 (Cary, North Carolina) for analysis. Managing weight during the previous four weeks (MW) or not (Not-MW) was tested for significant association with other surveyed variables by fitting the data to a logistic regression model with data weighted to reflect the age, sex and geographic distribution (Perth metropolitan or regional WA) within WA [25]. Backwards elimination was used to remove non-significant variables. Due to the number of tests conducted statistical significance in all cases was accepted at $\mathrm{P}<0.01$.

\section{RESULTS}

\subsection{Overall}

A total of 2734 eligible telephone numbers were called resulting in the completion of 1805 questionnaires, a response rate of $66 \%$. A larger proportion of respondents (56\%) were aged 35 - 54 than are found in WA (49\%) [25]. The demographic characteristics and BMI of the MW and Not-MW groups are presented in Table 1. Across all demographic strata presented in Table 1 the MW group ( $\mathrm{n}=978,54 \%)$ had higher BMI than the NotMW group ( $\mathrm{n}=827,46 \%)$. Fitting the data to a logistic regression model, (weighted as described), compared with the Not-MW group the likelihood of managing weight (MW) after backwards elimination was significantly associated with females (OR 2.77, 95\% CI 2.19 -
$3.49, \mathrm{P}<0.0001$ ), higher BMI (OR per BMI unit 1.18, $95 \%$ CI $1.15-1.22, \mathrm{P}<0.0001)$ and annual income greater than $\$ 65,000$ (OR 1.48, 95\% CI $1.17-1.87, \mathrm{P}=$ 0.001). Age, urban status, education and SES were not associated with likelihood of managing weight during the previous four weeks. Figure 1 plots the proportion of males and females MW across six BMI groups.

In all but one BMI group a greater proportion of females were attempting to maintain or lose weight compared with males. Apart from females with a BMI of less than 20 at least one half of females in each BMI category were attempting to maintain or lose weight. Amongst males with a BMI of between 30 - 39.9, at least $60 \%$ were attempting to maintain or lose weight. The proportion of each BMI group engaged in MW peaked for both sexes during the BMI range $30-39.9$, defined as "Obese" [26]. Although representing only $1.7 \%$ of the sample the proportion of males attempting to manage their weight decreased to $40 \%$ among respondents with a BMI of greater than 40 .

\subsection{Selected Health Attitudes}

The importance of preventing disease, internal and external factors associated with weight management was explored by weight management status. Participants were asked to rate each of 11 statements concerning how personally important each was for their health. Table 2 pre-

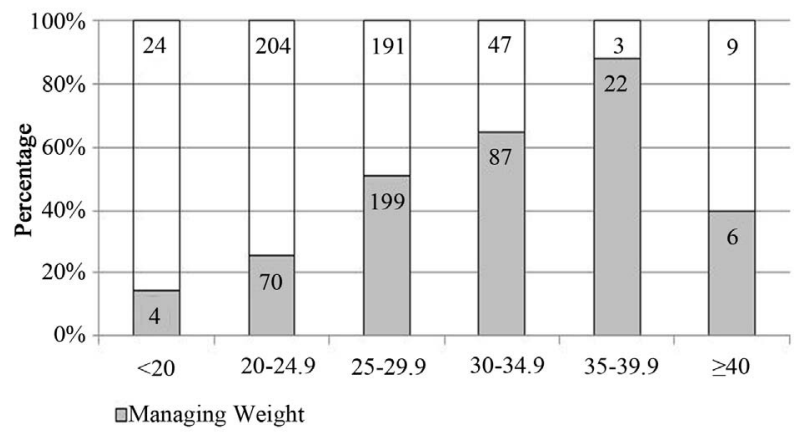

口Not-Managing Weight

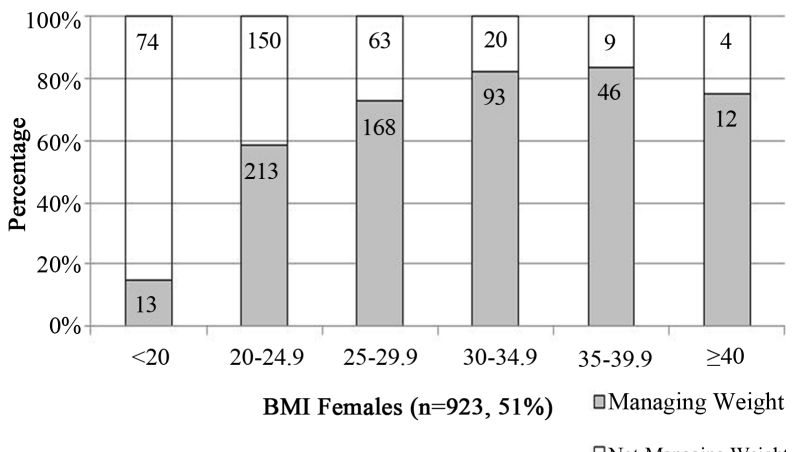

Figure 1. Proportion of males and females attempting to manage their weight by BMI group. 
Table 1. Respondent characteristics by recent weight management status.

\begin{tabular}{|c|c|c|c|c|c|c|}
\hline & \multicolumn{2}{|c|}{ Managing Weight ${ }^{\mathbf{b}}(\mathrm{n}=978)$} & \multicolumn{2}{|c|}{ Not Managing Weight ${ }^{b}(\mathrm{n}=827)$} & \multicolumn{2}{|c|}{ Overall $(n=1805)$} \\
\hline & $\mathrm{n}(\%)$ & BMI Mean (SD) & $\mathrm{n}(\%)$ & BMI Mean (SD) & n $(\%)$ & BMI Mean (SD) \\
\hline BMI & $978(100 \%)$ & $24.9(4.9)$ & $827(100 \%)$ & $27.9(5.1)$ & $1805(100 \%)$ & $26.5(5.2)$ \\
\hline \multicolumn{7}{|l|}{ Sex } \\
\hline Males & $394(40 \%)$ & $25.8(4.6)$ & $488(59 \%)$ & $28.5(4.3)$ & $882(49 \%)$ & $27.0(4.7)$ \\
\hline Females & $584(60 \%)$ & $23.6(5.0)$ & $339(41 \%)$ & $27.4(5.6)$ & $923(51 \%)$ & $26.0(5.7)$ \\
\hline \multicolumn{7}{|l|}{ Age group } \\
\hline $18-24$ & $67(7 \%)$ & $22.9(3.5)$ & $98(12 \%)$ & $24.9(4.5)$ & $165(9 \%)$ & $23.7(4.1)$ \\
\hline $25-29$ & $54(6 \%)$ & $23.7(4.1)$ & $60(7 \%)$ & $26.7(4.9)$ & $114(6 \%)$ & $25.1(4.7)$ \\
\hline $30-34$ & $97(10 \%)$ & $24.5(5.0)$ & $70(8 \%)$ & $27.7(5.0)$ & $167(9 \%)$ & $26.3(5.2)$ \\
\hline $35-39$ & $119(12 \%)$ & $25.6(5.3)$ & $118(14 \%)$ & $27.6(4.4)$ & $237(13 \%)$ & $26.6(4.9)$ \\
\hline $40-45$ & $163(17 \%)$ & $24.8(4.0)$ & $150(18 \%)$ & $27.3(5.2)$ & $313(17 \%)$ & $26.1(4.8)$ \\
\hline $46-49$ & $149(15 \%)$ & $25.1(4.3)$ & $110(13 \%)$ & $28.3(4.3)$ & $259(14 \%)$ & $26.9(4.6)$ \\
\hline $50-54$ & $120(12 \%)$ & $25.8(4.8)$ & $79(10 \%)$ & $29.2(5.8)$ & $199(11 \%)$ & $27.8(5.7)$ \\
\hline $55-65$ & $197(20 \%)$ & $25.9(6.3)$ & $142(17 \%)$ & $28.9(5.3)$ & $334(19 \%)$ & $27.6(5.9)$ \\
\hline \multicolumn{7}{|l|}{ Location } \\
\hline Perth metro & $490(50 \%)$ & $24.5(4.7)$ & $411(50 \%)$ & $27.6(5.1)$ & $901(50 \%)$ & $26.2(5.1)$ \\
\hline Regional WA & $488(50 \%)$ & $25.3(5.1)$ & $416(50 \%)$ & $28.2(5.1)$ & $904(50 \%)$ & $26.9(5.3)$ \\
\hline \multicolumn{7}{|l|}{ SES $^{\mathbf{a}}$} \\
\hline Disadvantaged & $110(11 \%)$ & $25.1(4.9)$ & $112(14 \%)$ & $29.1(4.7)$ & $222(12 \%)$ & $27.0(5.2)$ \\
\hline Middle & $451(46 \%)$ & $25.3(4.7)$ & $374(45 \%)$ & $28.3(5.4)$ & $825(46 \%)$ & $26.9(5.3)$ \\
\hline Advantaged & $401(41 \%)$ & $24.3(4.7)$ & $319(39 \%)$ & $27.1(4.7)$ & $720(40 \%)$ & $25.8(4.9)$ \\
\hline \multicolumn{7}{|l|}{ Education } \\
\hline Year 10 & $247(25 \%)$ & $25.9(5.1)$ & $220(27 \%)$ & $29.3(5.2)$ & $467(26 \%)$ & $27.7(5.5)$ \\
\hline Year 12 & $194(20 \%)$ & $25.5(4.9)$ & $180(22 \%)$ & $27.6(5.3)$ & $374(21 \%)$ & $26.6(5.2)$ \\
\hline Tertiary/TAFE & $518(53 \%)$ & $24.2(4.5)$ & $395(48 \%)$ & $27.3(4.8)$ & $913(51 \%)$ & $25.9(4.9)$ \\
\hline \multicolumn{7}{|l|}{ Income } \\
\hline$\leq \$ 65,000$ & $315(32 \%)$ & $25.5(5.5)$ & $283(34 \%)$ & $28.6(5.5)$ & $598(33 \%)$ & $27.1(5.7)$ \\
\hline$>\$ 65,000$ & $554(57 \%)$ & $24.6(4.2)$ & $422(51 \%)$ & $27.5(4.7)$ & $976(54 \%)$ & $26.3(4.7)$ \\
\hline
\end{tabular}

${ }^{\mathrm{a}}$ Socio-economic status, ${ }^{\mathrm{b}}$ Managing weight by attempting to lose or not gain weight.

sents the odds ratio for considering each statement important, stratified by weight management status. Overall, the majority of respondents rated each statement as important irrespective of their current weight management status.

When fitting the data to multivariate logistic regression model males and females who were maintaining or losing weight were approximately four times more likely to consider losing weight important than people not maintaining or losing their weight. The importance of disease, internal control or external support was not significantly associated with managing or not managing weight in this study.

\subsection{Weight Management Related Actions}

Participants were asked to indicate how often they monitored or carried out physical activity and food related behaviours (Table 2, Q2). Respondents who reported "often", "almost always" or "always" carrying out the behaviour were considered to be "frequent" adopters.

Amongst both males and females monitoring physical activity and food consumption frequently was significantly associated with managing weight. Fitting these data to multivariate models with BMI and income included, first separately for each sex and then overall with sex included as a fixed effect, people MW during the previous four weeks were significantly more likely to be monitoring the amount of food they consume, limit portions sizes and track amount of physical activity compared with people Not-MW. Females managing their weight were twice as likely as Not-MW females to track their physical activity for the week and the amount of food eaten each day. Amongst males tracking the amount 
Table 2. Health attitudes rated "important" and behaviours, by sex and weight management status.

\begin{tabular}{|c|c|c|c|c|}
\hline & Q1. How important is it to you that you $\cdots$ & $\begin{array}{l}\text { Females }(\mathrm{n}=923) \\
\quad \text { OR }(95 \% \mathrm{CI})\end{array}$ & $\begin{array}{l}\text { Males }(\mathrm{n}=882) \\
\text { OR }(95 \% \mathrm{CI})\end{array}$ & $\begin{array}{l}\text { Overall }(\mathrm{n}=1805) \\
\quad \text { OR }(95 \% \mathrm{CI})\end{array}$ \\
\hline \multirow{4}{*}{ Disease } & Lower the risk of cancer? & NS & NS & NS \\
\hline & Lower the risk of heart disease? & NS & NS & NS \\
\hline & Lower the risk of diabetes? & NS & NS & NS \\
\hline & Maintain a healthy weight? & NS & NS & NS \\
\hline \multirow[t]{2}{*}{ Weight } & Not gain weight? & NS & $2.38(1.22,4.65)^{\mathrm{a}}$ & $2.01(1.19,3.38)^{\mathrm{b}}$ \\
\hline & Lose weight? & $4.21(2.78,6.34)^{\mathrm{a}}$ & $3.65(2.44,5.46)^{\mathrm{a}}$ & $3.79(2.83,5.07)^{\mathrm{b}}$ \\
\hline \multirow{2}{*}{ Internal } & Have more energy? & NS & NS & NS \\
\hline & Feel more in control? & NS & NS & NS \\
\hline \multirow{3}{*}{ External } & Be healthy for family and friends? & NS & NS & NS \\
\hline & Follow recommended guidelines? & NS & NS & NS \\
\hline & Set a good example for others? & NS & NS & NS \\
\hline \multirow{4}{*}{ Monitor } & $\begin{array}{l}\text { Q2. In the last four weeks did you”.. } \\
\text { “often”, “almost always”, “always”... }\end{array}$ & & & \\
\hline & Track your physical activity for the week? & $2.00(1.34,3.00)^{\mathrm{a}}$ & NS & $1.47(1.11,1.95)^{\mathrm{b}}$ \\
\hline & Track the kinds of foods you eat each day? & NS & NS & NS \\
\hline & Track the amount of food eaten that day? & $1.91(1.28,2.84)^{\mathrm{a}}$ & $1.81(1.28,2.56)^{\mathrm{a}}$ & $1.81(1.37,2.40)^{\mathrm{b}}$ \\
\hline \multirow{2}{*}{$\begin{array}{l}\text { Physical } \\
\text { Activity }\end{array}$} & Work physical activity into your day? & NS & NS & NS \\
\hline & Suggest PA to family or friends? & $0.45(0.30,0.67)^{\mathrm{a}}$ & NS & $0.68(0.51,0.88)^{\mathrm{b}}$ \\
\hline \multirow{4}{*}{ Food } & Choose a healthier food option? & NS & NS & NS \\
\hline & Limit the size of food servings? & $2.93(1.97,4.35)^{\mathrm{a}}$ & $3.83(2.69,5.45)^{\mathrm{a}}$ & $3.34(2.56,4.37)^{\mathrm{b}}$ \\
\hline & Refuse food when not hungry? & $0.58(0.40,0.84)^{\mathrm{a}}$ & NS & NS \\
\hline & Bring healthy food to social events? & NS & NS & $0.68(0.52,0.89)^{\mathrm{b}}$ \\
\hline
\end{tabular}

MW = Managing weight during previous four weeks by attempting to lose weight or stay the same, NS odds ratio not significant, ${ }^{\text {a }}<0.01$, (important vs. not), adjusted for BMI and income, ${ }^{b} \mathrm{P}<0.01$, (important vs. not), adjusted for BMI, income and sex.

of food eaten was significantly associated with managing weight while tracking physical activity was not.

Limiting the size of food servings was three times more likely amongst people managing their weight compared with people not managing their weight. The odds of suggesting physical activity to family or friends was negatively associated with managing weight, especially among females. Females who reported difficulty refusing food even when they were not hungry were twice as likely to be MW as females who did not report difficulty refusing food.

\subsection{Attitudes, Actions and Success}

Of the 1805 respondents 978 (54\%) were MW within the last four weeks with $41 \%(n=404)$ reporting they successfully maintained or lost weight (234 females and 170 males). Success or not in MW was not associated with importance placed on disease, internal or external weight control or weight status (Table 2, Q1) after adjusting for BMI and income. When the weight management actions (Table 2, Q2) were regressed with both BMI and income included then overall the two behav- iours associated with reporting success were keeping track of the amount of food eaten during each day (OR $2.10,95 \%$ CI $1.19,3.67, \mathrm{P}=0.0099)$ and suggesting physical activity to family and friends (OR 3.70, 95\% CI $1.84,7.44, \mathrm{P}=0.0002$ ). Amongst males the only behaveiour associated with success was suggesting a physical activity when meeting family or friends. Males who reported this were six times more likely to also report having been successful (OR 6.95, 95\% CI 2.41, 20.04, P = 0.0003 ). Among females the only behaviour associated with reporting success was refusing offers of food when not hungry (OR 5.63, 95\% CI 2.45, 12.97, $\mathrm{P}<0.0001$ ).

\section{DISCUSSION}

This paper set out to investigate the characteristics of adults maintaining or losing weight within four weeks prior to the survey and the relationship between their attitudes towards health and actions to maintain or lose weight. The results show that adults in this study who were managing their weight in the four weeks prior to the survey were, ceteris paribus, merely trying not to gain or lose weight because of their BMI or perceived 
weight status. Females were nearly three times more likely to be intentionally managing their weight compared with males, a finding similar to previous research [3]. In addition to gender, BMI status and annual income over $\$ 65,000$ were significantly associated with managing weight. Similar to Bloskstra et al. [27] and Mcquire [9] this study found bivariate associations with managing weight and increasing age, and that age was confounding the stronger underlying association between managing weight and a person's BMI. Furthermore, the results of this study suggest the majority of females were attempting to manage their weight when their BMI reached 20, while among males a clear majority attempting to MW was only seen when their BMI reached above 30 , a finding in keeping with Bloskstra et al. who reported that men consider their weight to be "just right" until they are obese [27].

The current study showed that the likelihood of MW within four weeks prior to the survey peaked for both sexes when BMI reached obese levels, $(\mathrm{BMI}=30$ - 39.9), suggesting that among people categorised as obese most were attempting to manage their weight. What is not clear from the current study is the length of time that people may have been attempting to manage their weight and whether their BMI has changed over that period. The results of this study also suggest that at least some males and females were not attempting to maintain their weight in the four weeks prior to the survey, irrespective of their BMI status.

Interestingly the raw proportion of MW among those with BMI $>40$ was not as high as among those with a BMI of $30-39(55 \%$ vs. $76 \%)$ although numbers in this morbidly obese category were small $(n=31)$. The health risks of being overweight have been publicly promoted for several years through mass media campaigns, particularly the risk of heart disease, cancer and diabetes. This was reflected in the majority of adults in this study who considered it important to lower their risk of developing these diseases, although in this study we observed no influence of perceived importance to lower risk of developing these diseases upon attempting to manage weight. Brink et al. had suggested that it was the diagnosis of disease that was the motivator for weight loss or risk of developing disease and the advice of a physician [4]. The results may also reflect a weakness in the questions to differentiate importance of lowering personal risk of developing these diseases between nested subgroups with differing prior diagnosis status, which might better predict recent weight management behaviour.

Other mediators of weight management explored in this study were the importance of having more energy and feeling more in control, neither of which were significant in predicting weight management. Being healthy for family and friends, following recommended guide- lines and setting a good example for others were also found to be important to all respondents, though not significantly more so among adults managing their weight. These findings suggest weight management behaviour may be autonomous as described by Williams et al. when exploring predictors of weight loss and maintenance among 128 patients [19]. However, Tinker and Tucker identified among women in a weight loss program that future health problems and appearance were associated with motivations for weight loss [28]. The results of this study may reflect underlying beliefs, or possibly the items selected as mediators were not adequately sensitive to detect significant difference between weight management status.

While we identified few mediation effects in this study people managing their weight were more likely to track their physical activity for the week and amount of food eaten that day, if not the kind of food they were eating. The use of dietary strategies such as consuming fewer calories and exercising more were common weight loss strategies reported in the literature [9,29]. Monitoring these behaviours may be an important action in weight management. Working physical activity into the day, which has been heavily promoted through social marketing campaigns in Western Australia, was not a frequent activity of people in the MW group. This suggests the possibility that physical activity remains a recreational pursuit, possibly even that physical activity may be viewed by some as a pursuit to be avoided regardless of their BMI. Adults in this study who were managing their weight in the four weeks prior to the survey limited the size of their food servings, a popular strategy among males who were MW and in line with weight loss strategies found elsewhere. Among females who reported finding it difficult to refuse food even when not hungry a significantly higher proportion were MW during the previous four weeks than among females who did not report this difficulty.

Success at MW was significantly associated with tracking food intake and being active with family and friends, the latter strategy seven times more likely to result in successful weight management among males. A limitation of the design of this study lies in the self-reported nature of the data. Objective measures such as the use of accelerometers to record physical activity and weighed food servings might serve to strengthen these findings, however among people attempting to lose weight the perceived value of healthy behaviour may be more important than the value of any physiological weight benefit.

\section{CONCLUSION}

The results of this study suggest that a person's BMI is the strongest predictor of attempts to manage their 
weight and that females are more likely to manage their weight at a lower BMI compared with males. Few other mediators of weight management were observed in this study, suggesting that further investigation into underlying motivations and attitudes towards weight management should be explored. The study also found that people who were managing their weight were monitoring daily food intake and physical activity to ultimately reduce calories and increase their level of exercise. These were important for adults who were successful in managing their weight and the association between these behaviours and successful weight management supports continued promotion of these healthy messages.

\section{IMPLICATIONS}

1) Though suggesting physical activity to family and friends was the least popular strategy health care professsionals should consider advising patients commencing a weight-management program that, at least in the current study, this behaviour was the most closely associated with success.

2) Among females, refusing foods when not hungry resulted in a 5.5 times greater likelihood of successful weight management. This suggests a supportive environment may potentially improve the likelihood of success among women tempted by opportunity though it remains unknown if reducing opportunities to eat will have the same impact as the ability to refuse food when offered.

\section{ACKNOWLEDGEMENTS}

Data were collected as part of the Draw the Line Healthy Weight campaign funded by the Western Australian Department of Health and supported by Diabetes WA, Cancer Council WA and Heart Foundation WA. The authors were commissioned to conduct an evaluation of that campaign and the results reported in this study were drawn from that evaluation.

\section{REFERENCES}

[1] Department of Health and Aging (2008) Submission to the House of Representatives Standing Committee on health and ageing inquiry into obesity in Australia. Submission No 154.

[2] World Health Organization (2006) Obesity and overweight. Fact Sheet 311. http://www.who.int/mediacentre/factsheets/fs311/en/

[3] Baranowski, T., Cullen, K.W., Nicklas, T., Thompson, D. and Baranowski, J. (2003) Are current health behavioural change models helpful in guiding prevention of weight gain efforts? Obesity Research, 11, 23S-43S. doi:10.1038/oby.2003.222

[4] Brink, P.J. and Ferguson, K. (1998) The decision to lose weight. Western Journal of Nursing Research, 20, 84-102. doi: $10.1177 / 019394599802000106$

[5] Visram, S., Crosland, A. and Cording, H. (2009) Triggers for weight gain and loss among participants in a primary care-based intervention. British Journal of Community Nursing, 14, 495-501.

[6] Sabinsky, M.S., Toft, U., Raben, A. and Holm, L. (2007) Overweight men's motivations and perceived barriers towards weight loss. European Journal of Clinical Nutrition, 61, 526-531.

[7] Adriaanse, M.A., de Ridder, D.T.D. and de Wit, J.B.F. (2009) Finding the critical cue: Implementation intentions to change one's diet work best when tailored to personally relevant reasons for unhealthy eating. Personality and Social Psychology Bulletin, 35, 60-71. doi: $10.1177 / 0146167208325612$

[8] Wammes, B., Kremers, S., Breedveld, B. and Brug, J. (2005) Correlates of motivation to prevent weight gain: A cross sectional survey. International Journal of Behavioural Nutrition and Physical Activity, 2, 1-8.

http://www.ijbnpa.org/content/pdf/1479-5868-2-1.pdf

[9] McGuire, M.T., Wing, R.R., Klem, M.L., Seagle, H.M. and Hill, J.O. (1998) Long-term maintenance of weight loss: Do people who lose weight through various weight loss methods use different behaviors to maintain their weight? International Journal of Obesity \& Related Metabolic Disorders, 22, 572-577.

doi:10.1038/sj.ijo.0800627

[10] Blokstra, A., Burns, C.M. and Seidell, J.C. (1999) Perception of weight status and dieting behaviour in Dutch men and women. International Journal of Obesity, 23, 718. doi:10.1038/sj.ijo.0800803

[11] Kuchler, F. and Variyam, J. (2003) Mistakes were made: Misperception as a barrier to reducing overweight. International Journal of Obesity, 27, 856-861. doi:10.1038/sj.ijo.0802293

[12] Bish, C.L., Blanck, H.M., Serdula, M.K., Marcus, M., Kohl 3rd, H.W. and Khan, L.K. (2005) Diet and physical activity behaviors among Americans trying to lose weight: 2000 behavioral risk factor surveillance system. Obesity Research, 13, 596-607. doi:10.1038/oby.2005.64

[13] Gregory, C., Blanck, H., Gillespie, C., Maynard, L. and Serdula, M. (2008) Perceived health risk of excess body weight among overweight and obese men and women: Differences by sex. Preventative Medicine, 47, 46-52. doi:10.1016/j.ypmed.2008.01.008

[14] Timperio, A., Cameron-Smith, D., Burns, C., Salmon, J. and Crawford, D. (2000) Physical activity beliefs and behaviours among adults attempting weight control. International Journal of Obesity, 24, 81-87. doi:10.1038/sj.ijo.0801089

[15] Bish, C.L., Blanck, H.M., Maynard, L.M., Serdula M.K., Thompson, N.J. and Khan, L.K. (2006) Health-related quality of life and weight loss among overweight and obese US adults, 2001 to 2002. Obesity, 14, 2042-2053. doi:10.1038/oby.2006.239

[16] Befort, C., Stewart, E., Smith, B., Gibson, C., Sullivan, D. and Donnelly, J. (2008) Weight maintenance, behaviors and barriers among previous participants of a universitybased weight control program. International Journal of 
Obesity, 32, 519-526. doi:10.1038/sj.ijo.0803769

[17] Elfhag, K. and Rössner, S. (2005) Who succeeds in maintaining weight loss? A conceptual review of factors associated with weight loss maintenance and weight regain. Obesity Reviews, 6, 67-85. doi:10.1111/j.1467-789X.2005.00170.x

[18] Fuglestad, P.T., Rothman, A.J. and Jeffery, R.W. (2008) Getting there and hanging on: The effect of regulatory focus on performance in smoking and weight loss interventions. Health Psychology, 27, S260-S270. doi:10.1037/0278-6133.27.3(Suppl.).S260

[19] Williams, G.C., Grow, V.M., Freedman, Z.R., Ryan, R.M. and Deci, E.L. (1996) Motivational predictors of weight loss and weight-loss maintenance. Journal of Personality and Social Psychology, 70, 115-126. doi:10.1037/0022-3514.70.1.115

[20] Wiltink, J., Dippel, A., Szczepanski, M., Thiede, R., Alt, C. and Beutel, M.E. (2007) Long-term weight loss maintenance after inpatient psychotherapy of severely obese patients based on a randomized study: Predictors and maintaining factors of health behavior. Journal of Psychosomatic Research, 62, 691-698. doi:10.1016/j.jpsychores.2006.12.014

[21] Wammes, B., French, S. and Brug, J. (2007) What young Dutch adults say they do to keep from gaining weight: Self-reported prevalence of overeating, compensatory behaviours and specific weight control behaviours. Public Health Nutrition, 10, 790-798. doi:10.1017/S1368980007258537

[22] Dutta-Bergman, M. and Youn, S. (1999) Profiling healthy eating consumers: A psychographic approach to social marketting. Social Marketting Quarterly, 5, 5-21.

[23] Australian Bureau of Statistics (2006) Census of population and housing: Socio-economic indexes for areas (SEIFA). http://www.abs.gov.au/AUSSTATS/abs@.nsf/Lookup/203 3.0.55.001Main+Features 12006

[24] Nothwehr, F., Dennis, L. and Haotong, W. (2007) Measurement of behavioral objectives for weight management. Health Education \& Behavior, 34, 793-809. doi: $10.1177 / 1090198106288559$

[25] Australian Bureau of Statistics (2006) Australian Bureau of Statistics Census Data 2006. http://www.abs.gov.au/websitedbs/D3310114.nsf/home/C $\underline{\text { ensus }+ \text { data }}$

[26] World Health Organization (2000) Obesity: Preventing and managing the global epidemic. http://libdoc.who.int/trs/WHO TRS 894.pdf

[27] Blokstra, A., Burns, C. and Seidell, J. (1999) Perception of weight status and dieting behaviour in Dutch men and women. International Journal of Obesity and Related Metabolic Disorders, 23, 7-17. doi:10.1038/sj.ijo.0800803

[28] Tinker, J.E. and Tucker, J.A. (1997) Motivations for weight loss and behavior change strategies associated with natural recovery from obesity. Psychology of Addictive Behaviors, 11, 98-106. doi:10.1037/0893-164X.11.2.98

[29] Kruger, J., Galuska, D.A., Serdula, M.K. and Jones, D.A. (2004) Attempting to lose weight: Specific practices among US adults. American Journal of Preventive Medicine, 26, 402-406. doi:10.1016/j.amepre.2004.02.001 